\title{
El español del occidente de Bolivia en la época de las independencias: notas fonético-fonológicas
}

\author{
José Luis Ramírez Luengo* \\ Universidad de Alcalá, España
}

\begin{abstract}
Resumen
Pese al interés que el español de Bolivia ofrece para la dialectología hispanoamericana, esta variedad sigue siendo una de las más desconocidas del continente, muy especialmente en lo que se refiere a su desarrollo diacrónico. Precisamente en esta línea, el presente trabajo pretende ser una contribución a la historia lingüística de Bolivia, en concreto de la zona andina del país; así, se pretenden describir los principales rasgos fonético-fonológicos que caracterizan esta variedad del español a principios del siglo XIX, a través del conjunto de cartas que María Guadalupe Cuenca de Moreno -criolla de clase alta, nacida en Chuquisaca en 1790- escribe a su marido desde Buenos Aires en 1811.
\end{abstract}

Palabras clave: español de América, historia de la lengua española, Bolivia, características fonético-fonológicas, siglo XIX.

\footnotetext{
* Investigador Contratado por el Programa Ramón y Cajal (Ministerio de Ciencia e Innovación).

Para correspondencia, dirigirse a: José Luis Ramírez Luengo (joseluis.ramirez@uah.es), Departamento de Filología, Facultad de Filosofía y Letras, Universidad de Alcalá, San José de Caracciolos, C/ Trinidad, 3 - 5, 28.801, Alcalá de Henares, Madrid, España.
} 


\title{
The western Bolivian Spanish at the time of Latin American INDEPENDENCE PROCESSES: PHONETIC AND PHONOLOGICAL NOTES
}

\begin{abstract}
Despite of the interest of Bolivian Spanish for Latin American dialectology, this variety is still one of the most unknown in the continent, specially from a diachronic point of view. This paper aims to be a contribution to the history of the Spanish language in the Andean part of the country. Thus, it describes the most important phonological features of this variety of Spanish at the beginning of 19th. century; the letters that María Guadalupe Cuenca de Moreno (high-level woman, born in Chuquisaca in 1790) writes to her husband from Buenos Aires in 1811 are the corpus used for this purpose.
\end{abstract}

Key words: Latin American Spanish, history of the Spanish language, Bolivia, phonological features, 19th Century.

Recibido: 20/12/09. Aceptado: 30/03/10.

1. Pese al manifiesto interés que por múltiples razones presenta para la dialectología hispanoamericana, el español de los territorios que hoy componen la República de Bolivia sigue siendo prácticamente desconocido desde todos los puntos de vista, de manera que no es exagerado decir que constituye-junto a otras zonas como Centroamérica o Paraguay-un auténtico hueco en blanco dentro del mapa lingüístico de la América hispana.

En efecto, por lo que se refiere a la sincronía, en estos momentos se cuenta ya con una serie de trabajos acerca de las variedades habladas en el país (entre otros, Coello Vila 1996; Lipski 1996: 204-218; Sanabria Fernández 1992; Varas Reyes 1960) que permiten hacerse una idea de las características fundamentales de las diversas regiones, pero que, a pesar de aportar datos interesantes, son claramente insuficientes, muy especialmente desde el punto de vista sociolingüístico. Por otro lado, es aún peor la situación de los estudios históricos, donde el panorama ha cambiado poco desde que Mendoza (1992: 413) indicaba que "no sólo tendríamos que hablar de escasez de estudios históricos del castellano desde la perspectiva lingüística, sino de una total inexistencia de tales estudios", al contar exclusivamente en estos momentos con trabajos muy parciales sobre la lengua del siglo XVI de la zona andina (Mendoza 1992), el uso de los pronombres y del sistema alocutivo de segunda persona (Gómez Seibane 2008; Ramírez Luengo 2003), o diferentes 
acercamientos al léxico, en especial del oriente del país (Egido Fernández 2006, 2007a, 2007b, 2008; Ramírez Luengo, en prensa).

Así pues, es del todo evidente la necesidad de llevar a cabo más estudios acerca de la evolución diacrónica del español en las regiones que hoy conforman Bolivia, con el propósito de conocer más profundamente la historia lingüística del país y, en concreto, la configuración de las diferentes variedades cultas que se emplean en él.

2. En esta línea, el presente trabajo pretende ser una contribución a la historia lingüística de Bolivia, más en concreto de la zona andina del país, que tradicionalmente se establece como una de las tres grandes zonas dialectales del mismo (Coello Vila 1996: 172-174; Lipski 1996, 210-212); así, se pretenden describir los principales rasgos fonético-fonológicos que caracterizan esta variedad del español a principios del siglo XIX, en el momento en que comienzan los procesos emancipadores en el continente ${ }^{1}$.

Con este propósito, se ha seleccionado como corpus de análisis las cartas que María Guadalupe Cuenca de Moreno envía desde Buenos Aires a su marido, el prócer argentino Mariano Moreno, entre el 14 de marzo y el 29 de julio de 1811; se trata de un conjunto de once misivas -en concreto, diez cartas y una pequeña esquela- en las que la autora narra a Moreno, en viaje hacia Inglaterra -y, en realidad, ya fallecido cuando su mujer le escribe- todo lo que constituye su vida diaria y los hechos que están aconteciendo en la capital argentina en esos momentos: por un lado, los aspectos cotidianos y familiares y las quejas de amor de la autora de los textos; por otro, los sucesos políticos que tienen lugar en los primeros momentos del proceso independentista rioplatense ${ }^{2}$.

1 En otras ocasiones se ha señalado ya la importancia del siglo XIX en la historia lingüística americana, pero conviene recordar una vez más que "los procesos emancipadores de comienzos de siglo suponen, desde el punto de vista de la lengua, la imposición de las nuevas capitales políticas como modelos normativos -que favorecen, por tanto, la normativización de los usos propios, desarrollados en momentos anteriores y divergentes de una zona a otra (Guitarte 1991: 72-73)-, a lo que se suma la hispanización lingüística de amplios grupos sociales del continente (Ramírez Luengo 2007: 28) y, con ello, la aparición de nuevas situaciones de contacto y variedades de español indigenizado" (Gómez Seibane y Ramírez Luengo, en prensa).

2 Para un estudio completo de las cartas en su contexto histórico, véase Álzaga (1967); en ese trabajo aparecen además, junto a la edición modernizada, los facsímiles sobre los cuales se ha llevado a cabo el presente estudio. 
Por lo que toca a la informante en sí, cabe recordar que María Guadalupe nace en Chuquisaca -hoy Sucre- en 1790, pertenece a una de las familias patricias de la ciudad y, tras quedar huérfana de padre, se educa en un convento de monjas de la ciudad (Álzaga 1967: 34); muy joven, con apenas catorce años, contrae matrimonio con Mariano Moreno, y en 1805 se traslada a Buenos Aires, donde estará viviendo hasta su muerte en 1850. Así pues, tales datos permiten ofrecer el perfil sociolingüístico de la autora de las cartas, de vital importancia para contextualizar adecuadamente los resultados que se extraigan del estudio: se trata de una mujer, perteneciente al nivel socioeducacional medio-alto de la época, y que ha vivido ya seis años en Buenos Aires en el momento en el que escribe los textos aquí analizados, aspecto fundamental que se debe considerar a la hora de comprender algunos de los fenómenos reflejados en ellos ${ }^{3}$.

Por otro lado, el hecho de que los materiales considerados pertenezcan al género epistolar y, más allá de eso, estén dirigidas a su marido, hace que en ellos se emplee un registro muy coloquial y un estilo muy cercano, lo que facilita la aparición de fenómenos que, de otra forma, no tendrían cabida en los usos escritos de la época ${ }^{4}$; por tanto, todo ello convierte a las cartas aquí analizadas en un corpus de primera importancia para el estudio del español empleado en la Bolivia andina de los albores del siglo XIX.

De este modo, todo lo indicado hasta el momento permite establecer las principales coordenadas que van a definir la lengua que se va a describir en el presente estudio: a la vista del perfil biográfico de la informante, se trata del idiolecto de una hablante que, desde el punto de vista diatópico, emplea la variedad de español del occidente boliviano, y desde lo diastrático hace uso de un sociolecto alto/culto; además, hay que tener en cuenta que la residencia más o menos prolongada en Buenos Aires - $y$, por tanto, el contacto interdialectal- puede tener importantes repercusiones lingüísticas, por lo que será necesario considerar este factor a la hora de analizar determinados fenómenos fonéticos.

3 En efecto, es probable que, como bien señala Penny (2004: 74-75) al describir situaciones semejantes, en el habla de María Guadalupe se hayan producido ya procesos de acomodación lingüística, en el marco del contacto interdialectal.

4 Ejemplo meridiano de lo aquí señalado lo constituye, por ejemplo, el caso del voseo, que presenta una situación especialmente interesante en este corpus, y que ha sido analizado ya en Ramírez Luengo (2003). 
3. Como es por todos sabido, el conocimiento de los fenómenos fonéticofonológicos que caracterizan a las diferentes variedades del español en otros momentos históricos solo se puede obtener a partir de la correcta interpretación de las grafías que aparecen en los textos, y muy especialmente de aquéllas que rompen las "tendencias ortográficas" (Frago 2002: 151) existentes en el momento en que tales textos se generan ${ }^{5}$; así, el análisis de la forma de escribir de María Guadalupe Cuenca parece establecer con cierta fiabilidad la existencia de determinados rasgos fónicos en su habla, lo que permite a su vez -y con las necesarias precauciones- caracterizar el español culto del occidente de Bolivia al final de la época colonial.

De este modo, cabe señalar en primer lugar la presencia de determinadas grafías que ponen en evidencia algunos fenómenos propios de la oralidad, tales como las simplificaciones vocálicas por contacto, en casos como acredor (carta 3$)^{6}$ o ayudar 'a ayudar' (carta 11), la dentalización de la $/ \mathrm{m} /$ final en el latinismo Tedeun (carta 2), o la labialización de la /n/ ante /f/, que tiene un reflejo muy frecuente en los textos, en ejemplos como emfermo (cartas 1,11), comfesarse (carta 2), triumfales (carta 5) o imflamacion (carta 5) entre otros; en los tres casos se trata, como bien dice Frago (1999: 209-210), de "la connivencia entre lo fónico y lo grafémico manifestada a propósito de pronunciaciones bastante corrientes" que, si bien resultan interesantes como muestra de la fonética de la informante, su propia generalidad en el español les resta importancia dialectal para la caracterización del español de la Bolivia andina decimonónica.

3.1. Más allá de esto, y por lo que se refiere ya al sistema vocálico, conviene señalar en primer lugar la presencia aún en esta época de algunos casos de vacilaciones en el vocalismo átono, habitualmente en forma de cierres de /e/ en /i/ (por ejemplo, dispierta, carta 4; dispierto, carta 8; espidicion, carta 10), pero también de /o/ en /u/ (pudian, carta 2) y, en tres ocasiones, de /a/ en /e/ (alagrare, carta 1; partecular, carta 2; paragueyos, carta 5);

A este respecto, es necesario recordar una vez más, como dice Frago (2002: 151), "la inexistencia, hasta fechas más recientes de lo que se suele pensar, de unas normas ortográficas cerradas, de alcance general y de común acatamiento". Para todo lo que tiene que ver con este tema, véase Frago (2002: 137-164).

${ }^{6}$ Para la numeración de las cartas se ha seguido el orden cronológico en el que las presenta Álzaga (1967); en concreto, tal numeración es la siguiente: 1) 14 de marzo de 1811;2) 20 de abril de 1811 ; 3) 1 de mayo de 1811;4) 9 de mayo de 1811;5) 25 de mayo de 1811;6) Sin fecha, mayo-junio de 1811 ; 7) 9 de junio de 1811;8) 21 de junio de 1811;9) 23 de junio de 1811 ; 10) 1 de julio de 1811 ; 11) 29 de julio de 1811 . 
se descubre, así, una situación muy semejante a la descrita para la centuria anterior en numerosas áreas americanas, tales como el Río de la Plata (Fontanella de Weinberg 1987: 96; Elizaincín et al. 1997: 32), el litoral argentino (Donni de Mirande 2004: 63-64) o, dentro de Centroamérica, Honduras y Guatemala (Ramírez Luengo 2004-2005: 59; Ramírez Luengo 2006: 263), y esta continuidad respecto al siglo XVIII -que Fontanella de Weinberg (1987 : 103) señala también para Buenos Aires- parece obligar a retrasar al siglo XIX la fecha en la que estas fluctuaciones vocálicas dejan de producirse en la norma culta, al menos en algunas de las regiones del continente americano ${ }^{7}$.

Junto a lo anterior, también se registran otras alternancias vocálicas que se pueden explicar por factores diferentes a la vacilación ya indicada: por un lado, se descubren diferentes formas del verbo escribir con /e/ (escrevir, cartas $1,3,9,10 ;$ escrevire, carta 3$)^{8}$, esto es, de la variante morfológica que Frago (1999: 41, 114) califica como anticuada ya en el siglo XVI, pero que resulta habitual todavía, por ejemplo, en los estratos populares del Uruguay decimonónico (Ramírez Luengo 2004: 316); por otro, se recoge un ejemplo de la forma mesmo (carta 4), con la vocal etimológica /e/, que constituye un uso único frente a la moderna mismo, mucho más frecuente.

Por lo que se refiere a los diptongos, el corpus pone de manifiesto una serie de fenómenos que afectan a estos elementos, y que van desde las muy ocasionales monoptongaciones -en concreto, quere (carta 7) y quen (carta 8)- que tal vez se puedan considerar simples lapsus cálami ${ }^{9}$, hasta las más frecuentes diptongaciones irregulares, que se concentran en la voz ausiencia (cartas $7,8,10)$ y en los presentes de los verbos entregar y ofender: entriegen (carta 3), entriega (carta 11), ofiendo (carta 11). A este respecto, no sorprende su aparición en tales elementos: en el primer caso, porque los derivados diptongados del sufijo latino - entia se descubren con cierta frecuencia hasta el siglo XVIII en diversas regiones de América como Guatemala (Ramírez

Es necesario distinguir estas alternancias /e/-/i/, /o/-/u/, fenómeno propio y habitual del español medieval y de los Siglos de Oro, de las que todavía se producen hoy en sociolectos bajos de la región como resultado de la influencia del quechua y del aimara (Coello Vila 1996: 175; Lipski 1996: 212; Van Wijk 1961: 54); dado el -prácticamente seguro-monolingüismo de la informante y su clase social, parece evidente que los ejemplos del corpus no tienen nada que ver con esta segunda posibilidad.

8 Que alternan, eso sí, con las mucho más abundantes (20 frente a cinco) variantes modernas con /i/, a veces, incluso en la misma carta: escrivirte (carta 1), escriviendote (carta 2), escriviria (carta 3), escrivi (carta 9).

9 Si bien el caso del verbo querer es citado por Mendoza (2008: 220) como presente en la actualidad en la Bolivia andina. 
Luengo 2006: 264) o Buenos Aires (Fontanella de Weinberg 1987: 53) ${ }^{10}$; en el segundo, porque formas verbales como las señaladas tampoco son desconocidas en otras zonas de América en los siglos XVIII y XIX (Ramírez Luengo 2004: 317; 2006: 264), de manera que los ejemplos aquí señalados -que se mantienen hasta el momento actual en esta variedad diatópica (Van Wijk 1961: 59)- no constituyen sino conservaciones en el español de la Bolivia andina de formas habituales en momentos anteriores también en otras zonas del continente.

En esta línea, se descubren también en el corpus analizado varios casos de diptongación de hiatos -linia (carta 6), y bolbeo 'volvió' (carta 4), por hipercorrección-fenómeno prácticamente general en América en el momento actual, incluida Bolivia (Van Wijk 1961: 53, 61; Mendoza 2008: 220), y que históricamente aparece en diversas zonas del continente desde los inicios de la colonización (Ramírez Luengo 2007: 41) ${ }^{11}$. A estos ejemplos se debe sumar la casi constante aparición de la forma Micaila 'Micaela' (cartas 1, $3,4,10)^{12}$, dislocación acentual que tampoco es desconocida en la zona (Van Wijk 1961: 59), pero que en las cartas solo se registra en esta voz, lo que tal vez esté manifestando la adquisición de esa forma ya con diptongo por parte de la informante, como resultado del contacto interdialectal con el español porteño ${ }^{13}$.

Por último, y de gran importancia desde el punto de vista dialectal, cabe señalar la pérdida de algunas vocales que se descubre en el texto: juramto (carta 2), algraré (carta 5), muchismo (carta 8) y Algandro (carta 8). Si bien en determinados casos se puede pensar en simples lapsus cálami, lo cierto

10 También aparece esta forma a comienzos del siglo XIX en la argentina Santa Fe (Donni de Mirande 2004: 263), a raíz de lo cual es posible sostener su pervivencia regional más allá del siglo XVIII, a semejanza de lo que ocurre - de acuerdo con el corpus aquí estudiado-con el occidente boliviano.

11 En el caso concreto de la región aquí estudiada, Frago (2007: 159) registra un ejemplo semejante-rial por 'real'- en un poema potosino de 1799, lo que parece demostrar la vigencia de este fenómeno en la zona al menos desde el siglo XVIII. Por otro lado, y según se señala en Ramírez Luengo (2004: 318), en el Uruguay de las primeras décadas del siglo XIX estos usos están reducidos a las clases más populares, mientras que -a juzgar por estos testimonios-en el caso del occidente de Bolivia se registra ya en las clases cultas; parece descubrirse, por tanto, una diferente valoración sociolingüística de este fenómeno, si bien es necesario llevar a cabo estudios más amplios para poder describir con cierta seguridad su distribución - diatópica, pero sobre todo diastrática- en el español de la América decimonónica.

12 En concreto, seis casos de diptongación (Micaila) frente a un único ejemplo de Micaela (carta 11).

13 Donde este fenómeno, de acuerdo con Fontanella de Weinberg (1987: 54), "parece que se daba hasta principios del siglo XIX en el habla culta". 
es que algunos de los ejemplos -en especial, los ya señalados muchismos y Algandro-parecen poner de manifiesto el proceso de pérdida vocálica que se produce en toda la zona andina boliviana (Gordon 1980: 349; Mendoza 2008: 219), y demuestran la vigencia de uno de los fenómenos más idiosincrásicos de esta variedad, las llamadas vocales caedizas, ya a principios del siglo XIX entre los grupos elevados de la sociedad ${ }^{14}$.

3.2. Por lo que se refiere al consonantismo, cabe señalar en primer lugar la presencia en estos años iniciales del siglo XIX de dos fenómenos que caracterizan a la variedad que se está describiendo en estas páginas: por un lado, la total ausencia de yeísmo, que se traduce en el corpus en el perfecto empleo de las grafías $<\mathrm{y}, \mathrm{i}>\mathrm{y}<\mathrm{ll}>$ para la palatales central y lateral respectivamente ${ }^{15}$; por otro, la imposición ya en esta época del seseo, reflejado en abundantísimas cacografías del estilo de asierto (carta 1), rais (carta 2), Mendosa (carta 3), paseño (carta 3), isiste (carta 4), cabesa (carta 4), serrada (carta 5), escases (carta 6), comicion (carta 7), gaseta (carta 8), aserlo (carta 9), quisas (carta 10), sercado (carta 10), priciones (carta 11) o gimenes (carta 11), que aparecen en todas las cartas y en todo tipo de voces, tanto habituales como más cultas, y tanto comunes como nombres propios. Por supuesto, no puede sorprender lo inmediatamente expuesto, dada la existencia de ambos rasgos en el español actual de la Bolivia andina (Lipski 1996: 210; Gordon 1980: 350), así como en los textos del siglo XVI analizados por Mendoza (1992: 418); sirven estos ejemplos, por tanto, como atestiguación decimonónica del mantenimiento de la situación que al parecer se impone en la región desde sus orígenes, y se va a mantener sin cambios hasta el momento actual.

14 En contraste, se descubren también varios ejemplos de adiciones vocálicas, en el caso de tamibien (carta 4) y en el nombre del prócer argentino José Domingo French, que aparece escrito como Frenches (carta 2); tal grafía se registra también en el diario del boliviano José S. Vargas (2008: 105, 106, 146), lo que hace pensar que probablemente refleje la pronunciación real de la época.

15 Es de sobra conocido que el hecho de que un fenómeno fónico no se plasme en un texto no quiere decir que no exista en el habla de su autor; ahora bien, la plasmación de otros rasgos dialectales en él -como, por ejemplo, el seseo-y la perfecta adecuación de las grafías de las palatales en las muy numerosas ocasiones en que ambos fonemas se emplean hacen pensar que, efectivamente, el yeísmo no era propio del idiolecto de María Guadalupe, algo que avala, además, el hecho de que el español boliviano actual tampoco sea yeísta (Gordon 1980: 350; Coello Villa 1996: 175; Lipski 1996: 210-211), y solo ahora comience a extenderse este fenómeno entre los más jóvenes, en ciudades como Santa Cruz de la Sierra y La Paz. 
Junto a lo anterior, cabe señalar otra serie de aspectos que parecen reflejar también fenómenos propios de la variedad de español hablada en el occidente de Bolivia. Así, por ejemplo, en las cartas se encuentran algunos casos de pérdida de /d/ que, si bien en ocasiones tal vez se puedan considerar meros lapsus-Medallas e Fernando (carta 6)-, en otras sin duda se deben relacionar con la pérdida de este elemento que se descubre en la región (Lipski 1996: 212): intente 'intendente' (carta 3) y aonde 'adonde/donde', registrado en varias ocasiones (cartas 2 y 4 ) y probablemente lexicalizado en esa forma; también lexicalizada está, en sentido contrario, la adición de la /d/ inicial en el verbo 'entrar' y todos sus derivados: dentrada (carta 2), dentrar (cartas 37 8), dentra (carta 4), dentro 'entró' (carta 6), que, según Cuervo (1955: 823), aparece desde antiguo en el español de diversas regiones, y que hoy es habitual en los niveles populares del occidente boliviano.

En el caso de las vibrantes, cabe señalar en primer lugar la caída de la simple en posición intervocálica, si bien los dos ejemplos registrados aparecen en el término declaración (declacion, carta 4; declaciones, carta 11), de manera que tal vez se trate de un uso lexicalizado, reducido exclusivamente a esa voz. Por otro lado, se descubre en numerosas ocasiones la representación de la vibrante múltiple con el grafema simple $<\mathrm{r}>$, en los nombres de los próceres Veruti 'Berruti' (carta 2) y Gutieres 'Gutiérrez' (carta 2), la denominación del batallón Ariveños 'Arriveños' (carta 3) o incluso voces comunes como bario 'barrio' (carta 3); si bien es cierto que grafías como las señaladas aparecen en el siglo XIX en diferentes zonas americanas y no poseen ninguna trascendencia fónica (Frago 2007: 155156), el hecho de que en el occidente de Bolivia se produzca en ocasiones la igualación de ambas vibrantes (Gordon 1980: 351) obliga a considerar también la posibilidad de que, en el caso de los textos aquí analizados, los ejemplos señalados sean indicio, precisamente, de que tal igualación se produce ya en estos momentos.

Por último, se descubren también en el corpus dos cacografías que parecen indicar la sonorización ocasional de las oclusivas sordas: guarteles (carta 10) y un cumplimiendo (carta 1) enmendado en el esperable cumplimiento. Aunque su interpretación no sea fácil, el hecho de que en la variedad aquí analizada se produce en ocasiones, de acuerdo con Mendoza (2008: 21), el ensordecimiento de las oclusivas tal vez permita entender ambos casos -si bien con las naturales reservas- como hipercorrecciones que están manifestando la vigencia de este fenómeno ya al comenzar el siglo XIX.

Por otro lado, se recoge también en el corpus un ejemplo de refuerzo velar del diptongo inicial [we] -en concreto guesos (carta 2)-, fenómeno que, pese a su estigmatización actual, no parecía ser estrictamente vulgar en momentos anteriores, como el siglo XVIII, a juzgar por su abundante 
presencia en escritos de carácter culto, tanto en España (Gómez Seibane y Ramírez Luengo 2007: 58, 84) como en América (Fontanella de Weinberg 1987: 64; Sánchez Méndez 1997: 94); de este modo, su empleo en este corpus probablemente se pueda interpretar como una evidencia del mantenimiento de este prestigio todavía en la primera parte del siglo XIX, si bien será necesario llevar a cabo más estudios que confirmen este aserto ${ }^{16}$.

Así mismo, también resultan escasas cuantitativamente una serie de cacografías que parecen manifestar la existencia, en esta variedad de español, de fenómenos como la confusión de líquidas implosivas (Balbastro 'Barbastro, cartas 3, 8), o los trueques consonánticos, de /f-/ por /x-/ (Junes 'Funes', carta 8) y de /b/ por /g/ (Gustamante 'Bustamante', cartas 1,3). Sorprende, sin duda, la presencia de tales fenómenos, dado que el primero se desconoce en la Bolivia occidental y los dos siguientes, si bien tienen gran difusión geográfica desde antiguo (Cuervo 1955: 722, 740), no se suelen asociar al nivel socioeducacional medio/alto que representa el corpus estudiado; ahora bien, el hecho de que sus escasas apariciones se concentren exclusivamente en nombres propios parece evidenciar que los ejemplos indicados, en realidad, no corresponden tanto a características del habla de María Guadalupe Cuenca como al aprendizaje de tales nombres -al igual que el anterior caso de Micaila - con esa forma concreta, hecho que se refuerza, además, por la presencia de los tres fenómenos indicados en el Buenos Aires de la época (Fontanella de Weinberg 1987: 66, 100, 102) ${ }^{17}$.

En parte semejante a lo anterior, cabe también relacionar con la prolongada estancia en Buenos Aires las cacografías que parecen poner de manifiesto una posible aspiración de la /-s/ implosiva por parte de la autora de las cartas aquí estudiadas:

1. Decian q. ${ }^{\mathrm{e}}$ tenia lombrises $\mathrm{p}^{\mathrm{r}}$ haver echado una pocas (carta 4)

2. Yo me veo en esta cosas (carta 4)

3. Me parese q. ${ }^{\mathrm{e}}$ las gentes no estan gustosa $\mathrm{p} .{ }^{\mathrm{r}} \mathrm{q} .{ }^{\mathrm{e}}$ no se a bisto (carta 5)

4. El regalo q. ${ }^{\mathrm{e}}$ les isite de las Medallas (carta 6).

16 Por lo que se refiere a Buenos Aires -lugar de residencia de María Guadalupe-, Fontanella de Weinberg (1987: 64) señala que "el refuerzo consonántico (...) parece generalizarse aún más en el siglo XVIII, ya que aparecen abundantes grafías que lo testimonian"; tales grafías perduran también en el siglo XIX, tanto en esta región (Fontanella de Weinberg 1987: 102) como en la vecina Santa Fe (Donni de Mirande 2004: 273).

17 Esta interpretación se ve favorecida, además, por el hecho de que la totalidad de apariciones de los nombres de Barbastro y Bustamante aparezcan con la grafía señalada más arriba; más dificultades presenta, sin embargo, el caso de Funes, que se escribe en tres ocasiones con $\langle\mathrm{f}>$ y en una única con $\langle\mathrm{j}>$. 
En efecto, aunque es posible detectar algunos casos de aspiración en el occidente de Bolivia (Gordon 1980: 350), lo cierto es que esta región se caracteriza precisamente por la pronunciación sibilante de la /-s/ implosiva (Coello Vila 1996: 175; Lipski 1996: 211), de manera que es probable que la aspiración -y siempre y cuando los ejemplos señalados respondan a tal fenómeno y no sean meros lapsus cálami- se produzca como resultado del contacto continuado con la variedad porteña del español, donde estos usos se dan desde antiguo y están fuertemente asentados ya en los primeros años del siglo XIX (Fontanella de Weinberg 1987: 97-98).

Por último, presenta un notable interés analizar la situación de los denominados grupos cultos latinos, ya que, de acuerdo con Lapesa (1985: 421), tras la convivencia de los resultados simplificados y no simplificados que se produce en el siglo XVIII, en esta misma centuria triunfa la tendencia a la reposición, que pasará, así, a convertirse en la solución propia de la norma culta; sin embargo, parece que tal cronología no es aceptable para todas las regiones del dominio hispánico, pues en el caso de Buenos Aires, y según señala Fontanella de Weinberg (1987: 103), "las fluctuaciones que aún existen en las grafías hasta mediados de siglo testimonian la vacilación de los hablantes, que debían omitirlas muy frecuentemente en la realización oral" ${ }^{\prime 18}$.

En el caso de la Bolivia andina, el corpus aquí analizado manifiesta, a diferencia de la situación porteña, un empleo constante de los resultados con consonante repuesta, semejante, pues, al de la norma culta actual: perfecta (cartas 3, 5, 8), bictoria (carta 5), accion (carta 5) ${ }^{19}$; admitido (carta 3); indignos (carta 3$)^{20}$. Difiere, sin embargo, en los grupos triconsonánticos [ks

18 Tal situación se descubre también en el Uruguay de las primeras décadas del siglo XIX, donde el porcentaje de empleo de las variantes plenas y simplificadas parece estar determinado por motivaciones de tipo sociolingüístico (Ramírez Luengo 2004: 319-320). A partir de mitad de siglo -y de nuevo en el caso de Buenos Aires-, Fontanella de Weinberg (1987: 103) indica que "la visible disminución de alteraciones en la representación de los grupos cultos por parte de autores de nivel socioeducacional elevado, a medida que avanza el siglo XIX, muestra el marcado progreso de una normalización de la lengua en los niveles culturales más altos".

19 Esta voz se recoge también en una ocasión con la grafía $\langle\mathrm{cs}\rangle$ : acsion (carta 5). En esta línea, y dado el carácter seseante de María Guadalupe Cuenca, a veces el grupo [ks] aparece con la grafía $\langle\mathrm{cc}>$ en lugar de la (actualmente) normativa $\langle\mathrm{x}>$ : flucciones (carta 1), reflecciones (carta 11).

20 Los únicos casos en los que se produce la reducción de los grupos cultos son, una vez más, nombres propios de personajes argentinos, lo que obliga a pensar-como en el caso de Junes por Funes y Gustamante por Bustamante- en que María Guadalupe los adquiere con tal forma. En concreto, se registra una vocalización en Caudevila 'Capdevila' (carta 4) y la simplificación de dos grupos finales, en Argeri 'Argerich' (cartas 1, 4) y Biamon 'Viamonte' 
+ cons.], [ns + cons.], pues en este contexto la simplificación es la solución más empleada, al aparecer en catorce de los 18 ejemplos registrados -esto es, el 88,88 \% de los casos-, en voces como espreciones (cartas 1,2), espuesta (carta 4), pretestos (carta 3), mostruo (carta 1) o ystalacion (carta $2)^{21}$. Se puede decir, por tanto -y siempre y cuando los datos de este corpus sean extrapolables a la generalidad del español hablado en el occidente de Bolivia- que, por lo que respecta a los grupos cultos, la reposición de las consonantes implosivas es un proceso prácticamente concluido en el habla de los estratos cultivados de la región ${ }^{22}$, algo que coincide con las apreciaciones de Lapesa (1985: 421) y resulta coherente, además, con el consonantismo firme que caracteriza la variedad del español aquí analizada.

4. De este modo, el análisis desarrollado hasta el momento pone de manifiesto la presencia en el español de María Guadalupe de una serie de características que se pueden explicar por la diastratía o diatopía a las que la autora de las cartas pertenece: por un lado, cabe mencionar fenómenos como la alternancia de vocales átonas, la diptongación irregular -lexicalizada en diferentes elementos- o el refuerzo velar al diptongo [we], cuya presencia en una hablante de nivel sociocultural elevado se explica por ser fenómenos que muy posiblemente aún no están estigmatizados en las primeras décadas del siglo XIX ${ }^{23}$. Por otro, los orígenes geográficos de la informante explican

(cartas 7,8); nótese que este último ejemplo parece demostrar que el nombre del gobernador de Buenos Aires se pronunciaba en la época omitiendo la /e/ final.

21 Tampoco es semejante el empleo de las variantes simplificadas/no simplificadas en ambos grupos, ya que, mientras que en el caso de [ns + cons.] ambas posibilidades se reparten al 50\%, en el de [ks + cons.] la simplificación alcanza el 85,71\%; además, los dos únicos ejemplos que presentan $<\mathrm{x}+$ cons. $>$-en principio, grafía que denota la pronunciación triconsonántica- son voces que aparecen simplificadas en otras ocasiones, de manera que no es improbable que la supuesta variación sea, en este caso, meramente gráfica.

22 Por supuesto, cabe plantearse si tal reposición es fónica o meramente gráfica, algo que constituye una cuestión difícil de dilucidar. Por otro lado, esta descripción parece ser aplicable, así mismo, a otros niveles de la sociedad altoperuana de la época, pues una pequeña cala en el Diario del Tambor Vargas (2008) -bilingüe de escasa formación, nacido también a finales del siglo XVIII en el departamento vecino de Oruro- evidencia una situación muy semejante a la aquí descrita.

23 Esto parece poner de manifiesto que entre este momento y el actual se ha producido en el español hablado en la Bolivia occidental un cambio normativo que ha afectado a diversos elementos como los inmediatamente señalados, y que se puede extender también a otros no exclusivamente fónicos: por ejemplo, dentrar y todos sus derivados, que a la luz de este análisis parecen ser aceptables en la norma culta de comienzos del ochocientos, siguen siendo habituales 
algunas otras de las características fónicas que dejan traslucir sus escritos, tales como las vocales caedizas, la ausencia de yeísmo, la desaparición ocasional de la /d/ intervocálica, el tratamiento de los grupos cultos y -en caso de que sean algo más que meras cacografías- el ensordecimiento de las oclusivas (reflejado en varias hipercorrecciones en este caso) y la no distinción entre las vibrantes múltiple y simple.

Ahora bien, las particulares circunstancias vitales de María Guadalupe -en concreto, su permanencia durante años en la capital argentina- obligan a tener en cuenta los procesos de acomodación lingüística que pueden haber tenido lugar entre el idiolecto aquí analizado y la variedad porteña del español. De este modo, es probable que ese contacto sirva para reforzar algunas características fónicas propias del dialecto natal de la esposa de Mariano Moreno -tales como la diptongación de los hiatos o el seseo-, así como para introducir en su habla otras que, presentes en Buenos Aires, son desconocidas en el español de la Bolivia occidental, como son la aspiración de la /-s/ implosiva, la dislocación acentual, la confusión en las líquidas implosivas y los trueques consonánticos de $/ \mathrm{f}-/$ por $/ \mathrm{x}-/ \mathrm{y} / \mathrm{b} /$ por $/ \mathrm{g} /$; de hecho, el que los cuatro últimos fenómenos indicados aparezcan en exclusividad en nombres propios parece muestra evidente de que se producen no tanto en el habla de la informante en general, sino más bien en determinadas voces exclusivamente.

Más allá de esto, lo que el presente análisis parece demostrar es que, como era de esperar, en estos momentos -y como resultado de la dialectalización anterior $^{24}$ - existe ya una variedad de español propia de la Bolivia andina, que desde el punto de vista fónico coincide en muchos aspectos con la empleada actualmente en la región, pero que cuenta en su nivel culto con determinados fenómenos que hoy no son aceptables en este diastrato. Queda, pues, por analizar el momento en que se produce la configuración de tal

actualmente en los sociolectos bajos de La Paz, pero no en la norma culta. Se hace una vez más evidente, por tanto, que resulta "del todo imprescindible el desarrollo de una Historia de la norma lingüística, que permita poner en perspectiva los resultados de los estudios y determinar de forma objetiva, por ejemplo, qué rasgos son o no son vulgares en determinado momento, más allá de juicios de tipo impresionista" (Ramírez Luengo 2004-2005: 54).

24 Aunque aún no hay demasiados estudios sobre la cuestión, en el caso del altiplano mexicano Company (2007) ha demostrado cómo tal proceso se cumple en el siglo XVIII, motivado -o favorecido- por determinados hechos históricos que tienen lugar en la Centuria Ilustrada; es aún necesario llevar a cabo trabajos semejantes para el caso del Alto Perú, pero no es descabellado pensar que este proceso de determinación normativa que conlleva la dialectalización se produzca en esta región en el mismo momento, o quizá algo antes, ya en el siglo XVII. 
variedad dialectal, así como los procesos que van a producir posteriormente los cambios de valoración normativa que se han citado más arriba.

Así pues, es mucho lo que queda por analizar aún acerca de la prácticamente desconocida historia del español de Bolivia, cuyo estudio será necesario llevar a cabo sobre corpus abundantes que reflejen la variación lingüística inherente a toda lengua y presenten una total fiabilidad filológica ${ }^{25}$; por ahora, queden estas páginas no solo como una llamada de atención sobre la necesidad de desarrollar tales investigaciones, sino también como un primer intento de conocer y describir cómo suena el español que van a hablar en esta región los hombres y mujeres que comenzarán los movimientos emancipadores de Hispanoamérica.

25 A este respecto, cabe señalar la existencia de dos colecciones documentales filológicamente fiables acerca de la parte occidental (Mendoza 2001) y oriental (Egido Fernández 2001) de la actual República de Bolivia, si bien en ninguno de los casos se presentan textos que vayan más allá de los últimos años del siglo XVIII. 


\section{REFERENCIAS BIBLIOGRÁFICAS}

Álzaga, EnRique W. 1967. Cartas que nunca llegaron. María Guadalupe Cuenca y la muerte de Mariano Moreno. Buenos Aires: Emecé Editores.

Coello Vila, Carlos. 1996. Bolivia. En Manuel Alvar (dir.): Manual de dialectología hispánica: el español de América, pp. 169-184. Barcelona: Ariel.

COMPANY, Concepción. 2007. El siglo XVIII y la identidad lingüística de México. Discurso de ingreso a la Academia Mexicana de la Lengua (10 de noviembre de 2005). México DF: Universidad Nacional Autónoma de México - Academia Mexicana de la Lengua.

Cuervo, RuFino J. 1955. Apuntaciones críticas sobre el lenguaje bogotano. Bogotá: Instituto Caro y Cuervo.

Donni De Mirande, Nélida E. 2004. Historia del español en Santa Fe del siglo XVI al siglo XIX. Buenos Aires: Academia Argentina de Letras

Egido Fernández, Ma'. Cristina. 2001. III. Bolivia: b) Santa Cruz de la Sierra. Siglos XVI y XVII. En Elena ROJAS (coord.). Documentos para la Historia Lingüistica de Hispanoamérica III [Edición en CD-Rom]. Tucumán: Universidad Nacional de Tucumán. 2006. Una carta del siglo XVIII desde Moxos (Oriente de Bolivia). En José J. Bustos Tovar y José L. Girón Alconchel (eds.): Actas del VI Congreso Internacional de Historia de la Lengua Española, pp. 2189-2204. Madrid: ArcoLibros. 2007a. Una muestra del español oriental boliviano en el siglo XVIII. En César Hernández Alonso y Leticia Castañeda San Cirilo (eds.): El español de América. Actas del VI Congreso Internacional de "El español de América", pp. 915-926. Valladolid: Diputación de Valladolid.

2007b. El español de indígenas bilingües en el oriente boliviano (Moxos, siglo XVIII). En Concepción Company y José G. Moreno de Alba (eds.): Actas del VII Congreso Internacional de Historia de la Lengua Española, II, pp. 1577-1594. Madrid: ArcoLibros.

2008. Aspectos léxicos en documentación colonial del oriente boliviano (s. XVII-XVIII). En Actas del XV Congreso Internacional de la Asociación de Lingüistica y Filología de América Latina (ALFAL) [Edición en CD-Rom]. Montevideo: ALFAL.

Elizaincín, Adolfo, Marisa Malcouri y Virginia Bertolotti. 1997. El español en la Banda Oriental del siglo XVIII. Montevideo: Universidad de la República.

Fontanella de Weinberg, M. Beatriz. 1987. El español bonaerense. Cuatro siglos de evolución lingüistica (1580-1980). Buenos Aires: Hachette.

Frago, Juan A. 1999. Historia del español de América. Textos y contextos. Madrid: Gredos. 2002. Textos y normas. Comentarios lingüísticos. Madrid: Gredos.

2007. Tradición e innovación en el español americano de la Independencia. Romance Philology 61/2: 147-191.

Gómez Seibane, Sara. 2008. El sistema pronominal átono en la documentación altoperuana del siglo XVIII. En Actas del XV Congreso Internacional de la Asociación de Lingüística 
y Filología de América Latina (ALFAL) [edición en CD-Rom]. Montevideo: ALFAL, 2008.

Gómez Seibane, Sara y José L. Ramírez Luengo. 2007. El castellano del Bilbao en el siglo XVIII: materiales para su estudio. Bilbao: Universidad de Deusto.

en prensa. La edición de textos lingüísticos del siglo XIX: reflexiones sobre algunos ejemplos de la zona vasca. Ponencia presentada en el Congreso Internacional Tradición e innovación: nuevas perspectivas para la edición y el estudio de documentos antiguos, Madrid, España.

Gordon, Alan M. 1980. Notas sobre la fonética del castellano en Bolivia. En Alan M. Gordon y Evelyn Rugg (eds.): Actas del VI Congreso Internacional de Hispanistas, pp. 349-352. Toronto: University of Toronto.

Guitarte, Guillermo L. 1991. Del español de España al español de veinte naciones. La integración de América en el concepto de lengua española. En César Hernández Alonso et al. (eds.): El español de América. Actas del III Congreso Internacional de El español de América, pp. 65-87. Valladolid: Junta de Castilla y León.

LAPESA, Rafael. 1985. Historia de la lengua española. Madrid: Gredos.

LIPSKI, JoHn M. 1996. El español de América. Madrid: Cátedra.

Mendoza, José G. 1992. El castellano del siglo XVI en Bolivia. En César Hernández Alonso (coord.): Historia y presente del español de América, pp. 413-436. Valladolid: Junta de Castilla y León.

2001. III. Bolivia: a) Alto Perú. Siglos XVI-XVIII”. En Elena ROJAS (coord.): Documentos para la Historia Lingüística de Hispanoamérica III [Edición en CD-Rom]. Tucumán: Universidad Nacional de Tucumán.

2008. Bolivia. En Azucena Palacios (coord.): El español en América. Contactos lingüísticos en Hispanoamérica, pp. 213-236. Barcelona: Ariel.

Penny, RalPh. 2004. Variación y cambio en español. Madrid: Gredos.

Ramírez Luengo, José L. 2003. Contribución a la historia del voseo: el paradigma altoperuano a inicios del siglo XIX. Estudios Filológicos 38: 179-188.

2004. Variación diastrática en la historia del español: algunos ejemplos del Uruguay del siglo XIX. Boletín de la Real Academia Española 84/290: 307-330.

2004-2005. Contribución a la historia del español de Honduras: edición y estudio de documentos hondureños del siglo XVIII. Anuario de Letras 42-3: 51-75.

2006. Aproximación al español de Guatemala en el siglo XVIII: algunas características fonético-fonológicas. Lexis 30/2: 259-72.

Ramírez Luengo, José L. 2007. Breve historia del español de América. Madrid: ArcoLibros.

en prensa. El léxico del español del oriente boliviano en el siglo XVIII: una aproximación. En María D. Kítova-Vasíleva (ed.): Actas de la I Conferencia Internacional de Lingüistica Románica. Sofía: Nueva Universidad Búlgara (en prensa).

Sanabria Fernández, Hernando. 1992. El habla popular de Santa Cruz. La Paz: Librería Editorial Juventud.

SÁnchez Méndez, Juan P. 1997. Aproximación histórica al español de Venezuela y Ecuador durante los siglos XVII y XVIII. Valencia: Tirant lo Blanch.

Vargas, José S. 2008. Diario de un combatiente de la Guerra de la Independencia. 18141825. La Paz: ABNB/Fundación Cultural BCB/ Plural Editores.

VAN WiJK, HenRI L. 1961. Los bolivianismos fonéticos en la obra costumbrista de Alfredo Guillén Pinto. Boletín de Filología de la Universidad de Chile 13: 49-78.

Varas Reyes, Víctor. 1960. El castellano popular en Tarija. La Paz: Impreso Boliviano. 